\title{
Depletion of 5-HT Disrupts Prepulse Inhibition in Rats: Dependence on the Magnitude of Depletion, and Reversal by a 5-HT Precursor
}

Eric P. M. Prinssen, Ph.D., Marie-Bernadette Assié, Ph.D., Wouter Koek, Ph.D., and Mark S. Kleven, Ph.D.

The 5- $\mathrm{HT}_{1 \mathrm{~A}}$ agonist 8-OH-DPAT has been reported to disrupt prepulse inhibition (PPI) of the acoustic startle reflex after local administration into the raphe nuclei. Because it is likely that 8-OH-DPAT disrupted PPI by activation of somatodendritic inhibitory receptors, and thereby, via a decrease in 5-HT neurotransmission, we tested whether chronic, drug-induced, depletions of 5-HT have similar effects. Rats were drug-treated for three consecutive days and tested in a short PPI paradigm on day 4 , and retested $2 \mathrm{~h}$ later, after acute saline or drug administration. Repeated treatment with the 5-HT synthesis inhibitor $\mathrm{p}$-chlorophenylalanine methyl ester (PCPA; $160 \mathrm{mg} / \mathrm{kg}$ ) produced a small, but significant, attenuation of PPI, and a large decrease in extracellular 5-
HT levels in the hippocampus, as measured in independent microdialysis experiments. An even larger depletion of 5HT was obtained by substituting the $3^{\text {rd }}$ PCPA administration with the 5-HT releaser d-fenfluramine (10 $\mathrm{mg} / \mathrm{kg}$ ); this combined treatment nearly abolished PPI in the majority of animals. The involvement of 5-HT in the latter effects was confirmed by the finding that low doses of the 5-HT precursor 5-hydroxy-L-tryptophan reinstated PPI during retest. These data, together with recently published studies, provide strong evidence that pharmacologicallyinduced depletion of 5-HT disrupts PPI.

[Neuropsychopharmacology 26:340-347, 2002] (C) 2002 American College of Neuropsychophar macology. Published by Elsevier Science Inc. All rights reserved.
KEY WORDS: Prepulse inhibition; Startle reflex; Microdialysis; Serotonin; $p$-chlorophenylalanine; d-fenfluramine; 5-hydroxytryptophan

Prepulse inhibition (PPI) of the startle response refers to the phenomenon that a startle response to a strong stimulus is reduced when this stimulus is preceded by a small prestimulus within a short time period (Graham

From the Centre de Recherche Pierre Fabre, Castres, France Address correspondence to: Eric P.M. Prinssen, Ph.D., Centre de Recherche Pierre Fabre, 17 avenue Jean Moulin, F-81106 Castres Cédex, France, Tel.: + 335637142 33, Fax: + 335637143 63, E-mail: eric.prinssen@pierre-fabre.com

Received March 23, 2001; revised June 26, 2001; accepted July 30, 2001.

Online publication: $8 / 1 / 01$ at www.acnp.org/citations/ Npp080101158
1975). The paradigm has gained interest both clinically and preclinically as it was observed that certain patient populations such as schizophrenics, and animals treated with psychotogenics, show attenuated PPI (Swerdlow et al. 1986; Geyer and Braff 1987). Early preclinical pharmacological studies of the mechanisms underlying PPI focused mainly on dopamine, but also on 5-HT, which appears to play an important role. For example, pharmacologically-induced release of 5-HT disrupts PPI in the rat (Padich et al. 1996; Martinez and Geyer 1997). More than one subtype of 5-HT receptor may be involved in these effects as selective stimulation of $5-\mathrm{HT}_{2 \mathrm{~A}}$ (Sipes and Geyer 1995; Padich et al. 1996), $5-\mathrm{HT}_{1 \mathrm{~B}}$ (Sipes and Geyer 1994, 1996), and 5- $\mathrm{HT}_{1 \mathrm{~A}}$ receptors (Rigdon and Weatherspoon 1992; Sipes and Geyer 1995) disrupts PPI in the rat. In contrast to the extensive examination of increased function, the effects of de- 
creased 5-HT function in PPI received less attention. Nevertheless, indirect evidence for such effects exists. That is, $5-\mathrm{HT}_{1 \mathrm{~A}}$ agonist-induced disruption of PPI can reflect the actions of these drugs either at postsynaptic $5-\mathrm{HT}_{1 \mathrm{~A}}$ receptors, or at somatodendritic receptors, which inhibit 5-HT neuronal firing and release (Sharp and Hjorth 1990; Blier et al. 1998). The finding that the $5-\mathrm{HT}_{1 \mathrm{~A}}$ agonist 8-OH-DPAT disrupts PPI after local administration in the raphe nuclei (Sipes and Geyer 1995), the main 5-HT neuron-containing nuclei, suggests that it acts on $5-\mathrm{HT}_{1 \mathrm{~A}}$ somatodendritic receptors, i.e., via a decrease in 5-HT neurotransmission. Here, we further studied whether decreases in 5-HT levels are indeed able to alter PPI, by examining the effects of chronic, drug-induced, 5-HT depletions.

We first examined the effects of repeated administration of the 5-HT synthesis inhibitor $p$-chlorophenylalanine (PCPA), because this reportedly leads to a large and selective depletion of 5-HT (cf., Koe and Weissman 1966; Sarnek and Baran 1975; Baldessarini and Griffith 1976). Repeated treatment with PCPA, at a dose (160 $\mathrm{mg} / \mathrm{kg}$ ) that is in the range of that commonly used, induced a clear depletion of 5-HT in microdialysis experiments, and a small, but significant, attenuation of PPI. In order to examine whether the disruption of PPI depends on the magnitude of the depletion, we tried to deplete 5-HT further. Because we wanted to avoid the use of higher doses of PCPA, in part because they have been reported to produce toxic effects (cf. Ikonomov et al. 1990), we treated animals with the same dose of PCPA $(160 \mathrm{mg} / \mathrm{kg})$ but substituted the 5-HT releaser dfenfluramine $(10 \mathrm{mg} / \mathrm{kg})$ for the $3^{\text {rd }}$ PCPA treatment. We hypothesized that the release of stored 5-HT in conditions where its synthesis was still blocked by PCPA would further deplete extracellular levels of 5-HT, whereas omitting the $3^{\text {rd }}$ administration of PCPA would not greatly influence the inhibition of 5-HT synthesis because of the very long half-life of this compound (Koe and Weissman 1966). As hypothesized, the combination treatment decreased hippocampal 5-HT to a greater extent, and now completely disrupted PPI. To provide further evidence that 5-HT was involved in the latter effects, we examined whether the 5-HT precursor 5-hydroxy-L-tryptophan (5-HTP), which is able to enhance 5-HT levels after treatment with PCPA (Koe and Weissman 1966), would reinstate prepulse inhibition.

\section{MATERIALS AND METHODS}

\section{Subjects}

Male Sprague-Dawley rats (Ico: OFA SD (I.O.P.S. Caw) Iffa Credo, Lyon, France) weighing $180 \pm 20 \mathrm{~g}$ on arrival, were group-housed in stainless steel cages with wire grid flooring $(n=6 /$ cage, internal dimensions: $26 \times$ $42 \times 18 \mathrm{~cm} ; \mathrm{W} \times \mathrm{L} \times \mathrm{H})$ in an environmentally con- trolled room (temperature $21 \pm 1^{\circ} \mathrm{C}$ and relative humidity $55 \pm 5 \%$ ) on a $12 \mathrm{~h}: 12 \mathrm{~h}$ light:dark cycle (lights on at 7:00 A.M.). Food (standard rat chow; AO4, UAR, Epinay sur Orge, France) and filtered $(0.22 \mu)$ water were continuously available. A 5-day acclimatization period was allowed before animals were used in experiments. Three days before test, the animals were moved to an environmentally controlled housing room, but remained group-housed ( $n=2-3$ / cage; in polypropylene cages containing bedding material, internal dimensions: $17 \times 38 \times 15 \mathrm{~cm}$ ) during the repeated treatment phase. Twenty-two hours before testing, the animals were individually housed in polycarbonate hanging cages with wire grid flooring (internal dimensions: $18 \times$ $31 \times 18 \mathrm{~cm}$ ), where they had free access to water, but not food. Animals were handled and cared for in accordance with the Guide for the Care and Use of Laboratory Animals (Institute of Laboratory Animal Resources on Life Sciences 1996), and the European Directive 86/ 609 , and the protocol (No. 210) was carried out in compliance with French regulations and with local ethical committee guidelines for animal research.

\section{Procedure}

During a 3-day treatment regimen, animals received a single daily IP injection: either three treatments with saline (abbreviated as SSS), three treatments with 160 $\mathrm{mg} / \mathrm{kg}$ PCPA (PPP), two treatments with $160 \mathrm{mg} / \mathrm{kg}$ PCPA followed by one treatment with saline (PPS), two treatments with saline followed by one treatment with $10 \mathrm{mg} / \mathrm{kg}$ d-fenfluramine (SSF), or two treatments with $160 \mathrm{mg} / \mathrm{kg}$ PCPA followed by one treatment with 10 $\mathrm{mg} / \mathrm{kg}$ d-fenfluramine (PPF). After each daily injection, animals were put back into their cages. On the fourth day, animals were transported in their home cages to the acoustic startle test room, where they were immediately placed in individual startle chambers and submitted to a first PPI session (i.e., test session). After the session, animals were placed back in their home cages, and returned to their housing room. Thirty minutes later, animals received a SC injection of saline to allow antagonism experiments (not conducted here), followed by an IP injection of saline or 5-HTP 45 min later; after every injection, they were returned to their home cage. Ten minutes after the second injection, animals were transported to the test room, and submitted to a second PPI session (i.e., retest session) that was identical to the first session (see below).

\section{Apparatus}

Four startle chambers (SR LAB San Diego Instruments, San Diego, Ca.) were used. Each chamber consisted of a transparent acrylic cylinder (inside diameter: $8.8 \mathrm{~cm}$, inside length: $18.4 \mathrm{~cm}$ ), resting on a Plexiglas base in a 
sound-attenuated, ventilated enclosure illuminated by a $15 \mathrm{w}$ lamp. White noise bursts were presented via a loudspeaker mounted $28 \mathrm{~cm}$ above the animal. Movements within the cylinder were detected by a piezoelectric accelerometer attached to the base. Response sensitivities were calibrated using a standard calibrator tube (San Diego Instruments), and were adjusted to 150 units. Sound levels were calibrated for accuracy using the A weighting scale of a sound level meter (Radio Shack, Tandy Corp., Fort Worth, TX).

\section{PPI Sessions}

In a PPI session three different trial types were presented against a continuous $70 \mathrm{~dB}$ background: no stimulus (NS), $118 \mathrm{~dB}$ pulse (pulse alone; PA) and $78 \mathrm{~dB}$ prepulse followed by a $118 \mathrm{~dB}$ pulse (prepulse-pulse; $\mathrm{ppP}$ ). The pulse duration was $40 \mathrm{msec}$, the prepulse duration $20 \mathrm{msec}$, and the interval between the end of the prepulse and the onset of the pulse $80 \mathrm{msec}$. Sessions started with a 5-min adaptation period after which the animals were submitted to 10 PA trials (included to induce habituation, such that habituation during the following PPI assessment would be minimized, and not used for further analysis), followed by $10 \mathrm{PA}, 10 \mathrm{ppP}$ and 3 NS trials in a pseudorandom order. The interval between trials was variable but with a median of $15 \mathrm{~s}$. The startle response of a trial was defined as the average of 100 consecutive samples of $1 \mathrm{~ms}$, that were recorded from the onset of the pulse. For each session, the median of the $10 \mathrm{ppP}$ and the last $10 \mathrm{PA}$ trials was calculated. Basal startle response was expressed as the median of the 10 PA trials. The percentage PPI was calculated as the [(median PA trials - median ppP trials) / median PA trials] $\times 100$.

\section{Microdialysis}

The method used in the present experiments has been described previously (Assié and Koek 1996). Briefly, on day 4 , after three days of treatment as described above, a microdialysis probe ( $2 \mathrm{~mm}$ length, $0.5 \mathrm{~mm}$ diameter) was implanted into the left hippocampus (stereotaxic coordinates: rostral $-4.8 \mathrm{~mm}$, lateral $+4.6 \mathrm{~mm}$, ventral $-7.5 \mathrm{~mm}$, from bregma and dura surface according to Paxinos and Watson (1986)) of anaesthetized rats (chloral hydrate, $400-500 \mathrm{mg} / \mathrm{kg} \mathrm{IP}$, and supplementary doses to maintain anesthesia). The probe was continuously perfused $(1.1 \mu \mathrm{l} / \mathrm{min})$ with artificial cerebrospinal fluid containing $1 \mu \mathrm{M}$ of the selective 5-HT reuptake inhibitor citalopram. Starting approximately $1 \mathrm{~h}$ after implantation perfusate was collected every $20 \mathrm{~min}$ and directly analyzed for 5-HT and 5-HIAA content using high performance liquid chromatography with electrochemical detection (DECADE detector, ANTEC Leyden BV). Data were acquired using a Beckman Gold system. Concentrations of 5-HT and 5-HIAA were estimated by comparing peak areas from the microdialysis samples with those of external standards of known concentration of compounds. The limit of detection for 5-HT ( 3 times baseline noise) was approximately $1 \mathrm{fmol} /$ $20 \mu \mathrm{l}$ sample. Approximately $2 \mathrm{~h}$ after implantation, when the 5-HT levels became relatively constant (cf. Assié and Koek 1996), three control samples were collected for each individual animal (SEM for the three samples was always less than $20 \%$ of the mean). Because there were no significant differences between the means of the three samples within any of the groups (repeated measures ANOVA, data not shown), the levels were expressed as the sum of the three measurements. At the end of the experiment, the animal was killed by decapitation and the brain was removed, frozen and sectioned in a cryomicrotome (Jung Frigocut 2800) to verify the placement of the probe.

\section{Data Analysis}

Data on 5-HT and 5-HIAA levels and on \% PPI in the first experiment were analyzed with Kruskall-Wallis $\mathrm{H}$-tests (and not with parametric tests because of the lack of homogeneity of variance). When significant, these tests were followed by 1-tailed Mann-Whitney U-tests, with the hypotheses that: (1) All groups show lower values than the SSS group. (2) The PPF group shows lower values than all other groups. In the second experiment, data on \% PPI were analyzed with a Kruskall-Wallis H-test, that, when significant, was followed by 1-tailed Mann-Whitney U-tests, with the hypothesis that higher doses of 5-HTP show greater \% PPI scores than the lowest dose of 5-HTP. Data on startle response were analyzed with Kruskall-Wallis H-tests, and, when significant, were followed by Mann-Whitney U-tests (2-tailed, because we had no directional hypotheses). Data on body weight, which showed normal distributions, were analyzed with Student $t$-tests. For all tests, a $p<.05$ was considered significant.

\section{Drugs}

The following drugs were used: $p$-chlorophenylalanine methyl ester $\mathrm{HCl}$ (PCPA), 5-hydroxy-L-tryptophan (5-HTP; Sigma, Saint Quentin Fallavier, France), and d-fenfluramine $\mathrm{HCl}$ (provided by J.L. Maurel, Centre de Recherche Pierre Fabre). All drugs were dissolved in distilled water and administered in a volume of $10 \mathrm{ml} / \mathrm{kg}$. Doses refer to the free base. Additional compounds that were used only for the microdialysis experiments were: 5 -HT creatinine sulfate, 5-hydroxyindole-3-acetic acid (5-HIAA; Sigma, Saint Quentin Fallavier, France), chloral hydrate (Acros, Geel, Belgium) and citalopram $\mathrm{HBr}$ (Lundbeck, Copenhagen, Denmark). 


\section{RESULTS}

\section{Effects of Treatment with PCPA, d-fenfluramine, or Their Combination on 5-HT Levels}

Compared with saline-treated controls, repeated treatment with PCPA for three days decreased extracellular 5 -HT levels in the hippocampus by $88.8 \%$ (Table 1 . Two days of PCPA treatment produced similar, but somewhat weaker effects (i.e., $80.2 \%$ decrease), whereas a single treatment with $\mathrm{d}$-fenfluramine produced a smaller, but still statistically significant, decrease in extracellular 5-HT levels (39.4\%). Treatment with both PCPA and d-fenfluramine produced the lowest extracellular 5-HT levels (95.0\% decrease), which were significantly lower than those produced by two days of PCPA $(p<.05)$, and tended to be lower than those produced by three days of PCPA $(p=.06)$. The extracellular levels of 5-HIAA were significantly reduced by $67.2 \%$ by the single treatment with d-fenfluramine. In the three other groups, in which PCPA was administered the first two days, the levels of 5-HIAA were decreased almost $100 \%$, which precluded further analysis of their possible differences.

\section{Effects of the 5-HT Depletions on PPI and Basal Startle Response}

Two criteria were applied to exclude results from individual animals that would make the calculations of PPI less valid: (1) When the median response to the PA trials was smaller than an a priori chosen minimum value (i.e., 10). (2) When more than 4 out of 10 PA or ppP trials contained at least one sample value that was greater than the upper detection limit (i.e., 4095). Animals that fulfilled any of these criteria in either of the two sessions were excluded from further PPI analysis (but not from the analysis of the basal startle response). Of the 52 animals used in this first experiment, two were excluded; one based on criterion 1 (which occurred dur- ing retest, in the PPF group), and one based on criterion 2 (which occurred during test, in the PPS group).

Median \% PPI differed among the groups during test $\left(\mathrm{H}_{4}=18.2, p<.005\right)$ and during retest $\left(\mathrm{H}_{4}=16.0, p<\right.$ .005; Fig. 1). Compared with saline-treated controls, animals treated with PCPA for three days showed a significant decrease in PPI scores (median values dropped from 68.8 to $46.4 \%, p=.01$, and from 68.9 to $44.5, p=$ .02 , during test and retest, respectively). Animals treated for two days with PCPA showed a significant decrease during test $(p=.01)$, but not during retest $(p>$ .1). Similarly, a single treatment with d-fenfluramine showed a significant decrease in PPI scores during test $(p=.04)$, but not during retest $(p>.1)$. Treatment with both PCPA and d-fenfluramine decreased the median $\%$ PPI to below zero $(p<.0001$ compared with SSS, and $p<.01$ compared with the other groups, both during test and retest). Nevertheless, the response to this treatment was quite variable as can be seen by the large interquartile range in Figure 1.

Median basal startle response differed during retest $\left(\mathrm{H}_{4}=11.1, p<.05\right)$, but not during test $\left(\mathrm{H}_{4}=6.3, p>.1\right)$. The animals treated with both PCPA and d-fenfluramine (PPF group), but none of the three other groups, showed a statistically significant attenuation in startle reactivity compared with saline-treated control animals during retest $(p=.02)$. There were no significant correlations between basal startle response (which was log-transformed for this analysis) and \% PPI in individual animals within any of the separate groups $(p>.1)$. When data from all five groups were analyzed together, statistically significant correlations between basal startle response and \% PPI were found for the test sessions $(r=.25, p<.05)$ and the retest sessions $(\mathrm{r}=.42, p<.01)$. However, the latter correlations lost their statistical significance when the PPF group was excluded $(\mathrm{r}=.05$ and $\mathrm{r}=.15$, for test and retest, respectively; both $p>.1$ ), suggesting that they were due to the fact that the animals in the PPF group showed significant decreases in both parameters.

Table 1. The Effects of Saline, $160 \mathrm{mg} / \mathrm{kg}$ PCPA, $10 \mathrm{mg} / \mathrm{kg}$ D-Fenfluramine, or Combinations Thereof, on Basal Hippocampal 5-HT and 5-HIAA Levels [Median Levels and the Interquartile Range (IQR)]. Levels Are Expressed in fmol (Sum of 3 Measurements, Each During $20 \mathrm{~min}$ )

\begin{tabular}{|c|c|c|c|c|c|c|c|}
\hline \multirow[b]{2}{*}{ Group $^{1}$} & \multirow[b]{2}{*}{$n$} & \multicolumn{3}{|c|}{ 5-HT } & \multicolumn{3}{|c|}{ 5-HIAA } \\
\hline & & median $^{2}$ & IQR & $\%$ decrease & median $^{2}$ & IQR & $\%$ decrease \\
\hline $\mathrm{SS}(\mathrm{S})$ & 9 & 82.3 & (79.9-143.7) & & 16267 & $(12947-19508)$ & \\
\hline PPP & 5 & $9.2^{*}$ & $(6.9-10.5)$ & 88.8 & $72.6^{*}$ & $(57.2-92.8)$ & 99.6 \\
\hline $\mathrm{PP}(\mathrm{S})$ & 5 & $16.3^{*}$ & $(12.3-16.3)$ & 80.2 & $184.8^{*}$ & $(146.6-309.6)$ & 98.9 \\
\hline SSF & 4 & $49.9^{*}$ & $(28.9-77.8)$ & 39.4 & $5329^{*}$ & $(4152-6749)$ & 67.2 \\
\hline PPF & 5 & $4.1^{*+}$ & $(3.8-5.8)$ & 95.0 & $106.6^{*}$ & $(96.9-150.3)$ & 99.3 \\
\hline
\end{tabular}

${ }^{1}$ Each letter represents 1 day of treatment: S: saline; P: $160 \mathrm{mg} / \mathrm{kg}$ PCPA; F: $10 \mathrm{mg} / \mathrm{kg}$ d-fenfluramine; (S): saline was administered on day 3 in 4 out of 14 animals.

2*Significantly smaller than the SS(S) group $(p<.05)$;

${ }^{+}$Significantly smaller than all other groups $(p<.05)$, except PPP $(p<.06)$. 

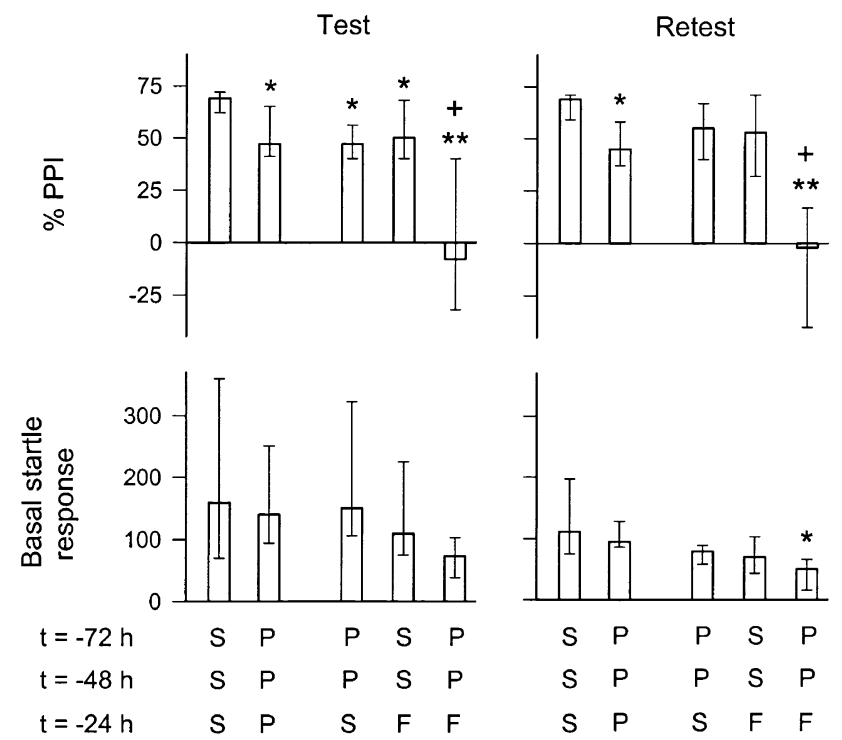

Figure 1. The effects of IP administration of saline (S), 160 $\mathrm{mg} / \mathrm{kg}$ PCPA (P), $10 \mathrm{mg} / \mathrm{kg}$ d-fenfluramine $(\mathrm{F})$, or combinations thereof, on $\%$ PPI ( $n=10 /$ group; upper panels) and basal startle response ( $n=10-11$ / group; lower panels). Basal startle response was expressed as the median of the pulse alone trials. Bars represent median values; error bars represent interquartile ranges. The test was performed on day 4 without any acute treatment, and the retest was performed $2 \mathrm{~h}$ later, after saline injections. ${ }^{*} p<.05,{ }^{* *} p<.01$ compared with the SSS group; ${ }^{+} p<.01$ compared with all other groups.

\section{Effects of 5-HTP on the Disruption of PPI by a 5 -HT Depletion}

Of the 41 animals used in this experiment, only one was excluded from the PPI analysis, based on criterion 1 (which occurred during retest, after acute treatment with $2.5 \mathrm{mg} / \mathrm{kg} 5-\mathrm{HTP})$. In this experiment, all animals were treated with both PCPA and d-fenfluramine, and consistent with experiment 1 , in the test sessions (i.e., before the administration of 5-HTP), the median \% PPI was close to 0 , except the group that was to receive 40 $\mathrm{mg} / \mathrm{kg}$ 5-HTP (median of $34.4 \%$; Figure 2). Nevertheless, the median \% PPI did not differ significantly between these four groups $\left(\mathrm{H}_{3}=4.5, p>\right.$.1). 5-HTP dosedependently reinstated PPI during retest $\left(\mathrm{H}_{3}=8.1, p<\right.$ .05 ) with a maximal effect (i.e., median $50.3 \%$ ) at 10 $\mathrm{mg} / \mathrm{kg}$. The median basal startle response was not significantly altered by $5-\mathrm{HTP}\left(\mathrm{H}_{3}=4.5, p>.1\right)$.

\section{General Effects of Treatment with PCPA, d-fenfluramine, or Their Combination}

Animals treated with PCPA alone, or in combination with d-fenfluramine, did not show any mortality, apparent sickness, or any gross behavioral abnormalities. However, the treatments affected the body weight of the

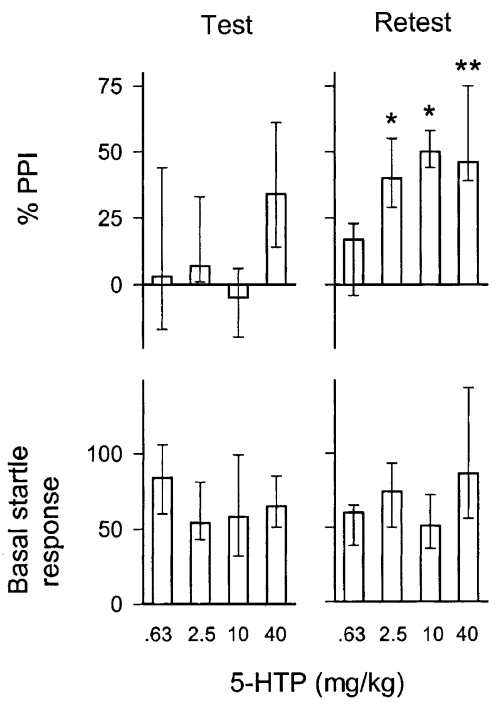

Figure 2. The effects of IP administration of 5-HTP during retest on \% PPI ( $n=10$ / group; upper panels) and basal startle response ( $n=10-11$ / group; lower panels) in animals treated with $160 \mathrm{mg} / \mathrm{kg}$ PCPA ( $\mathrm{t}=-72 \mathrm{~h}$ and $48 \mathrm{~h}$ ) and 10 $\mathrm{mg} / \mathrm{kg}$ d-fenfluramine $(\mathrm{t}=-24 \mathrm{~h})$. Basal startle response was expressed as the median of the pulse alone trials. Bars represent median values; error bars represent interquartile ranges. The test was performed without any acute treatment, and the retest was performed $2 \mathrm{~h}$ later, after 5 -HTP treatment. ${ }^{*} p<$ $.05,{ }^{* *} p<.01$ compared with the lowest dose.

animals, which are illustrated by the first experiment. Whereas the mean basal body weight on day 1 did not differ (range from 199 to $208 \mathrm{~g}$ in the five groups, $p>.1$ ), PCPA treatment during the first two days caused some loss of body weight, compared with a gain of body weight in saline-treated animals (mean \pm SEM: $-6.2 \pm 1.5 \mathrm{~g}$ and $15.7 \pm 0.85 \mathrm{~g}$, respectively; $p<.0001$ ). All animals lost body weight during the last $24 \mathrm{~h}$ due to the food-deprivation that we use routinely; however, d-fenfluramine reduced this loss of body weight both in animals treated with saline the first two days (body weight loss during the last $24 \mathrm{~h}:-28.0 \pm 1.1$ and $-23.1 \pm 0.71 \mathrm{~g}$, for the SSS and SSF groups, respectively; $p<.005)$ and in animals treated with PCPA the first two days $(-27.1 \pm 0.97$ and $-17.6 \pm$ $0.96 \mathrm{~g}$, for the PPS and PPF groups, respectively; $p<$ .0001). The changes in body weight did not appear to be related to effects on basal startle response or \% PPI. For example, animals treated with PCPA the first two days showed more weight loss than animals treated with both PCPA and d-fenfluramine whereas they showed less effects on basal startle response or \% PPI.

\section{DISCUSSION}

The most important findings in this study are that: (1) Depletion of 5-HT with the 5-HT synthesis inhibitor PCPA 
significantly attenuates PPI. (2) Further depletion of 5-HT by a combined treatment of PCPA with d-fenfluramine nearly abolishes PPI. (3) The latter effects can be reversed by acute treatment with the 5-HT precursor 5-HTP.

Repeated treatment with the 5-HT synthesis inhibitor PCPA leads to a large and selective depletion of 5-HT in vitro (Koe and Weissman 1966; Sarnek and Baran 1975; Baldessarini and Griffith 1976) and in vivo (Chen and Reith 1995; present study). In the present study, such a treatment regimen $(160 \mathrm{mg} / \mathrm{kg}$ for three days, once daily) attenuated the PPI of the acoustic startle reflex in rats without altering the basal startle response. These results are consistent with those of Fletcher et al. (2001), in a study that was published during the preparation of this manuscript, who reported a partial attenuation of the PPI of the acoustic startle reflex in rats after three days of treatment with $150 \mathrm{mg} / \mathrm{kg}$ PCPA, in the absence of an effect on basal startle response. In the same study, they showed that 5,7-DHT lesions of the raphe nuclei, the main 5-HT neuron containing nuclei, produced similar effects. Another recent study reported that tryptophan depletion, which is known to decrease 5-HT levels in the central nervous system, attenuated the PPI of acoustic startle stimuli in humans, without altering basal startle reactivity (Phillips et al. 2000). Taken together, these data suggest that depletions of 5-HT can attenuate PPI of the acoustic startle reflex both in rats and humans.

Because the PCPA regimen that we used decreased, but did not eliminate 5-HT, and attenuated, but did not abolish, PPI, we examined whether a larger depletion of 5-HT would produce a greater disruption of PPI. Therefore, we treated animals with PCPA in combination with the 5-HT releaser d-fenfluramine, which produced a larger decrease in hippocampal 5-HT than three or two treatments with PCPA alone (i.e., 95.0, 88.8; and 80.2\% decreases compared with saline-treated controls, respectively). This combination further reduced PPI as compared with PCPA alone, but was not without effects on basal startle reactivity (see below). We consider these effects of the combination as almost complete abolishment of PPI in the majority of animals, because, out of 50 animals treated with the combination in the current study, 28 showed PPI smaller than or equal to $10 \%$ during the test session (and 19 out of 50 showed PPI smaller than or equal to $0 \%$ ). The effects obtained with the PCPA d-fenfluramine combination suggest that only very marked decreases in 5-HT levels (i.e., $>95 \%$ ) are able to abolish PPI. Note, however, that the in vivo 5-HT measurements were performed to compare different treatment conditions with each other, and not to compare 5-HT levels with PPI performance. Moreover, the relation between 5-HT levels and \% PPI may depend on the treatment regimen; i.e., it is conceivable that chronic depletions, which often give rise to compensatory mechanisms (e.g., Davis and Sheard 1976; Heslop and Curzon
1999), require a greater decrease in 5-HT levels to abolish PPI than acute treatments. Further studies in which 5-HT is measured in awake animals, preferably during testing (cf. Lucas et al. 1997), may allow a more detailed examination of the relation between 5-HT and PPI levels. Nonetheless, the present results suggest that the magnitude of disruption of PPI depends on the magnitude of depletion of 5-HT.

The 5-HT precursor 5-HTP, which is able to enhance synaptic 5-HT levels in animals chronically treated with PCPA (Koe and Weissman 1966), dose-dependently reinstated PPI in animals treated with PCPA and d-fenfluramine. The compound was active at doses that are low, relative to those which have been used in other studies (e.g., Miczek et al. 1975; Gartside et al. 1992). This may have been due to a steep response curve for PPI after small changes in basal 5-HT levels (see above). The finding that low doses of 5-HTP reinstate PPI in 5-HT depleted animals is relevant because it: (1) Provides evidence, for the first time, that the effects on PPI of a treatment regimen that is known to deplete 5-HT, are really due to the depletion of 5-HT. (2) Validates the new combination regimen with PCPA and d-fenfluramine. The latter is especially important because, even though d-fenfluramine has some selectivity as a 5-HT releaser, it and its metabolites have a complex pharmacology (e.g., Garattini et al. 1987). The effects of the highest dose of 5 -HTP $(40 \mathrm{mg} / \mathrm{kg}$ ) were confounded by the fact that the disruption of PPI by the combination treatment was less important in this group of animals (median PPI of $34 \%$ compared with values close to 0 for the other four groups with the same condition in experiment 1 and 2), which makes the interpretation of the effect on PPI of this dose somewhat difficult. However, we would like to emphasize that the intermediate doses of 5-HTP (2.5-10 $\mathrm{mg} / \mathrm{kg}$ ) did not have this problem and showed significant effects compared with the lowest, inactive, dose $(0.63 \mathrm{mg} / \mathrm{kg})$. The high variability in \% PPI after the combination treatment suggests that future studies with 5 -HTP or other 5-HT agonists may use a larger $n$, or match the different groups by their 'test' results. In contrast with its effects on PPI, 5-HTP did not reverse the attenuation of basal startle response induced by the combination treatment of PCPA and d-fenfluramine. This is important because it shows that substantial PPI was possible in animals in which the basal startle response was attenuated. In other words, the near abolishment of PPI by the PCPA d-fenfluramine combination treatment was not due to a 'floor effect' in the prepulse-pulse trials (cf. Figure 3 in Swerdlow et al. 2000). The dissociation of PPI and basal startle response by 5 -HTP also suggests that these two phenomena are unrelated. This, together with the absence of a strong correlation between PPI and startle reactivity scores (see Results), suggests that the effects of the combination treatment on PPI can be ascribed to disrupted sensorimotor gating (cf. Swerdlow et al. 2000). 
The finding that 5-HTP did not reverse the attenuation of the basal startle response induced by the combination treatment suggests that it was not mediated by 5-HT depletion. Indeed, if anything, depletion of 5-HT has been reported to enhance startle reactivity (Conner et al. 1970; Walters et al. 1979). A possible explanation for the lack of such an effect in the present study may be the body weight loss that occurred, which may decrease startle reactivity (Fechter and Ison 1972), and neutralize the effects of 5-HT depletion (Walters et al. 1979). However, we found not only a lack of enhancement, but a significant decrease in basal startle response in animals treated with PCPA and d-fenfluramine. Because this occurred in animals that showed only intermediate body weight loss (see Results), it is likely that other factors also play a role, for example, a direct effect of the major metabolite of d-fenfluramine, d-norfenfluramine, at postsynaptic 5-HT receptors. Indeed, d-norfenfluramine, not d-fenfluramine, is known to persist relatively long (Clineschmidt et al. 1978), and it has affinity for several 5-HT receptors (e.g., Garattini et al. 1987). It is conceivable that interactions between body weight loss, 5-HT depletion, and direct effects of d-fenfluramine metabolites underlie the effects of the combination treatment on startle reactivity.

Based on their finding that 8-OH-DPAT significantly attenuated PPI when administered in the raphe nuclei of rats, Sipes and Geyer (1995) hypothesized that its effects were due to its ability to decrease 5-HT neuronal activity (e.g., Sharp and Hjorth 1990; Blier et al. 1998). However, as mentioned by the authors (Sipes and Geyer 1995), this hypothesis was only partly supported by the data because: (1) Systemic 8-OH-DPAT produced a greater disruption of PPI than its local administration in the raphe. (2) 8-OH-DPAT was equally active in the median and dorsal raphe nuclei, 3) the lowest dose of 8-OH-DPAT that was effective, was still relatively high $(5 \mu \mathrm{g})$; at this dose 8-OH-DPAT may diffuse to other brain areas (Jolas et al. 1995). Nevertheless, the present results showing that 5-HT depletion can (nearly) abolish PPI, like systemic 8-OH-DPAT, together with the finding by Fletcher et al. (2001) that 8-OH-DPAT does not further disrupt PPI in animals treated with PCPA (this was not true in animals lesioned with 5,7-DHT; the mechanism of this effect remains to be demonstrated; see discussion in Fletcher et al. (2001)), are in agreement with the hypothesis that the ability of 8-OH-DPAT to disrupt PPI is due to its effects on 5-HT neuronal firing and release. Taken together, several lines of evidence suggest that the ability of 8-OH-DPAT to disrupt PPI depends on its ability to alter 5-HT neurotransmission. Nevertheless, its site of action remains unclear and may involve somatodendritic $5-\mathrm{HT}_{1 \mathrm{~A}}$ receptors in several brain regions, and, possibly, postsynaptic $5-\mathrm{HT}_{1 \mathrm{~A}}$ receptors that regulate 5 - $\mathrm{HT}$ firing via a long-loop feedback mechanism (Bosker et al. 1997; Casanovas et al. 1999).
Pharmacologically-induced release of 5-HT disrupts PPI in rats (Padich et al. 1996; Martinez and Geyer 1997), but enhances PPI in humans (Vollenweider et al. 1999). A recent study by Fletcher et al. (2001) suggested that not only 5-HT release, but also 5-HT depletion, can disrupt PPI in rats. The present findings that marked 5-HT depletions nearly abolish PPI, and that this can be reversed by low doses of 5-HTP, shows the robustness and selectivity of this phenomenon. That similar effects may occur in humans (Phillips et al. 2000), suggests that tonic 5-HT neurotransmission plays a general, crossspecies, role in the expression of PPI. Which 5-HT receptor subtype(s) needs to be tonically activated to allow normal prepulse inhibition, and whether 5-HT depletion underlies the disruption of sensorimotor gating in certain patient populations, are some of the challenging and important questions for future studies.

\section{ACKNOWLEDGMENTS}

The authors thank Christelle Marc for technical assistance with the behavioral experiments, Valérie Rigal for technical assistance with the microdialysis experiments, and Joël Besnard and Christelle Marc for assistance with data management. Citalopram was kindly donated by Lundbeck (Copenhagen, Denmark).

\section{REFERENCES}

Assié MB, Koek W (1996): (-)-Pindolol and (+/-)-tertatolol affect rat hippocampal 5-HT levels through mechanisms involving not only $5-\mathrm{HT}_{1 \mathrm{~A}}$, but also $5-\mathrm{HT}_{1 \mathrm{~B}}$ receptors. Neuropharmacol 35:213-222

Baldessarini RJ, Griffith FF (1976): Acute increases by p-chlorophenylalanine of apomorphine-induced stereotyped behavior in the rat. Psychopharmacol 48:91-95

Blier P, Piñeyro G, El Mansari M, Bergeron R, De Montigny C (1998): Role of somatodendritic 5-HT autoreceptors in modulating 5-HT neurotransmission. Ann N Y Acad Sci 861:204-216

Bosker FJ, Klompmakers A, Westenberg HGM (1997): Postsynaptic $5-\mathrm{HT}_{1 \mathrm{~A}}$ receptors mediate 5-hydroxytryptamine release in the amygdala through a feedback to the caudal linear raphe. Eur J Pharmacol 333:147-157

Casanovas JM, Hervás I, Artigas F (1999): Postsynaptic 5-HT AA $_{1}$ receptors control 5-HT release in the rat medial prefrontal cortex. Neuroreport 10:1441-1445

Chen N-H, Reith MEA (1995): Monoamine interactions measured by microdialysis in the ventral tegmental area of rats treated systemically with ( \pm )-8-hydroxy-2-(din-propylamino)tetralin. J Neurochem 64:1585-1597

Clineschmidt BV, Zacchei AG, Totaro JA, Pflueger AB, McGuffin JC, Wishousky TI (1978): Fenfluramine and brain serotonin. Ann N Y Acad Sci 305:222-241

Conner RL, Stolk JM, Barchas JD, Levine S (1970): Parachlorophenylalanine and habituation to repetitive auditory startle stimuli in rats. Physiol Behav 5:1215-1219 
Davis M, Sheard MH (1976): p-Chloroamphetamine (PCA): acute and chronic effects on habituation and sensitization of the acoustic startle response in rats. Eur J Pharmacol 35:261-273

Fechter LD, Ison JR (1972): The inhibition of the acoustic startle reaction in rats by food and water deprivation. Learn Motiv 3:109-124

Fletcher PJ, Selhi ZF, Azampanah A, Sills SL (2001): Reduced brain serotonin activity disrupts prepulse inhibition of the acoustic startle reflex: effects of 5,7-dihydroxytryptamine and $p$-chlorophenylalanine. Neuropsychopharmacol 24:399-409

Garattini S, Mennini T, Samanin R (1987): From fenfluramine racemate to $\mathrm{d}$-fenfluramine. Specificity and potency of the effects on the serotoninergic system and food intake. Ann N Y Acad Sci 499:156-166

Gartside SE, Cowen PJ, Sharp T (1992): Effect of 5-hydroxyL-tryptophan on the release of 5-HT in rat hypothalamus in vivo as measured by microdialysis. Neuropharmacol 31:9-14

Geyer MA, Braff DL (1987): Startle habituation and sensorimotor gating in schizophrenia and related animal models. Schizophrenia Bull 13:643-668

Graham FK (1975): Presidential Address, 1974. The more or less startling effects of weak prestimulation. Psychophysiol 12:238-248

Heslop KE, Curzon G (1999): Effect of reserpine on behavioural responses to agonists at $5-\mathrm{HT}_{1 \mathrm{~A}}, 5-\mathrm{HT}_{1 \mathrm{~B}}, 5-\mathrm{HT}_{2 \mathrm{~A}}$, and 5- $\mathrm{HT}_{2 \mathrm{C}}$ receptor subtypes. Neuropharmacol 38:883-891

Ikonomov OC, Stoynev AG, Goranova-Stoyneva II, Popov A, Minkova VA (1990): Nephrotoxic effect of the specific brain serotonin depletor para-chlorophenylalanine. Acta Physiol Hung 76:191-199

Institute of Laboratory Animal Resources on Life Sciences (1996): Guide for the Care and Use of Laboratory Animals. Washington, DC, National Research Council

Jolas T, Schreiber R, Laporte AM, Chastanet M, De Vry J, Glaser T, Adrien J, Hamon M (1995): Are postsynaptic $5-\mathrm{HT}_{1 \mathrm{~A}}$ receptors involved in the anxiolytic effects of $5-\mathrm{HT}_{1 \mathrm{~A}}$ receptor agonists and in their inhibitory effects on the firing of serotonergic neurons in the rat. J Pharmacol Exp Ther 272:920-929

Koe BK, Weissman A (1966): p-Chlorophenylalanine: a specific depletor of brain serotonin. J Pharmacol Exp Ther 154:499-516

Lucas G, Bonhomme N, De Deurwaerdère P, Le Moal M, Spampinato U (1997): 8-OH DPAT, a 5- $\mathrm{HT}_{1 \mathrm{~A}}$ agonist and ritanserin, a $5-\mathrm{HT}_{2 \mathrm{~A} / \mathrm{C}}$ antagonist, reverse haloperidol induced catalepsy in rats independently of striatal dopamine release. Psychopharmacol 131:57-63

Martinez DL, Geyer MA (1997): Characterization of the disruptions of prepulse inhibition and habituation of startle induced by $\alpha$-ethyltryptamine. Neuropsychopharmacol $16: 246-255$

Miczek KA, Altman JL, Appel JB, Boggan WO (1975): Parachlorophenylalanine, serotonin and killing behavior. Pharmacol Biochem Behav 3:355-361

Padich RA, McCloskey TC, Kehne JH (1996): 5-HT modulation of auditory and visual sensorimotor gating .2. Effects of the 5- $\mathrm{HT}_{2 \mathrm{~A}}$ antagonist MDL 100,907 on disruption of sound and light prepulse inhibition produced by $5-\mathrm{HT}$ agonists in Wistar rats. Psychopharmacol 124:107-116

Paxinos G, Watson C (1986): The rat brain in stereotaxic coordinates ( $2^{\text {nd }}$ edition). New York, Academic Press

Phillips MA, Oxtoby EK, Langley RW, Bradshaw CM, Szabadi E (2000): Effects of acute tryptophan depletion on prepulse inhibition of the acoustic startle (eyeblink) response and the $\mathrm{N} 1 / \mathrm{P} 2$ auditory evoked response in man. J Psychopharmacol 14:258-265

Rigdon GC, Weatherspoon JK (1992): 5-Hydroxytryptamine ${ }_{1 \mathrm{~A}}$ receptor agonists block prepulse inhibition of acoustic startle reflex. J Pharmacol Exp Ther 263:486-493

Sarnek J, Baran L (1975): The effect of 5-hydroxytrytamine synthesis inhibitors on neuroleptic-induced catalepsy in rats. Arch Immunol Ther Exp 23:511-516

Sharp T, Hjorth S (1990): Application of brain microdialysis to study the pharmacology of the $5-\mathrm{HT}_{1 \mathrm{~A}}$ autoreceptor. $\mathrm{J}$ Neurosci Methods 34:83-90

Sipes TA, Geyer MA (1994): Multiple serotonin receptor subtypes modulate prepulse inhibition of the startle response in rats. Neuropharmacol 33:441-448

Sipes TA, Geyer MA (1995): 8-OH-DPAT disruption of prepulse inhibition in rats: reversal with $(+)$ WAY 100,135 and localization of site of action. Psychopharmacol 117:41-48

Sipes TE, Geyer MA (1996): Functional behavioral homology between rat $5-\mathrm{HT}_{1 \mathrm{~B}}$ and guinea pig $5-\mathrm{HT}_{1 \mathrm{D}}$ receptors in the modulation of prepulse inhibition of startle. Psychopharmacol 125:231-237

Swerdlow NR, Braff DL, Geyer MA, Koob GF (1986): Central dopamine hyperactivity in rats mimics abnormal acoustic startle response in schizophrenics. Biol Psychiatry 21:23-33

Swerdlow NR, Braff DL, Geyer MA (2000): Animal models of deficient sensorimotor gating: what we know, what we think we know, and what we hope to know soon. Behav Pharmacol 11:185-204

Vollenweider FX, Remensberger S, Hell D, Geyer MA (1999): Opposite effects of 3,4-methylenedioxymethamphetamine (MDMA) on sensorimotor gating in rats versus healthy humans. Psychopharmacol 143:365-372

Walters JK, Davis M, Sheard MH (1979): Tryptophan-free diet: effects on the acoustic startle reflex in rats. Psychopharmacology 62:103-109 